\title{
The effect of salts on the viscosity and wilt-inducing capacity of the capsular polysaccharide of Erwinia amylovora
}

\begin{abstract}
Water solutions of the capsular polysaccharide (EPS) of Erwinia amylovora exhibit long flow times $(\mathrm{t})$ in a kinematic viscometer. Addition of salts to the solutions greatly decreases the flow times. The salt-induced decrease in flow time is directly related to the ionic strength of the solution and independent of the ionic species present. The salt effect does not result from a change in the molecular weight of the EPS. Addition of $\mathrm{NaCl}$, at concentrations sufficient to reduce the flow time, decreases or eliminates the capacity of EPS solution to cause wilt in the cut shoot assay. Treatment of EPS with either of two depolymerase phages decreases both $t$ and the molecular weight of the EPS (from $100 \times 106 \mathrm{D}$ to less than $4 \times 104 \mathrm{D}$ ). Such phage-produced fragments ( $\gamma \mathrm{dp}$ ) retain their capacity to cause wilt in the cut shoot assay but, like EPS, lose this ability in the presence of salts. Radiolabeled EPS and $\gamma \mathrm{dp}$ is retained at the end of the cut shoot when wilt occurs but is distributed throughout the shoot when wilt is inhibited by salt.
\end{abstract}

Keyword: Salts; Polysaccharide; Erwinia amylovora; Wilt; EPS 